\title{
Effect of climatic factors on the seasonal fluctuation of human brucellosis in Yulin, northern China
}

\author{
Kun Liu ${ }^{1 \dagger}$, Zurong Yang ${ }^{1 \dagger}$, Weifeng Liang ${ }^{2}$, Tianci Guo ${ }^{1}$, Yong Long ${ }^{1}$ and Zhongjun Shao ${ }^{1 *}$
}

\begin{abstract}
Background: Brucellosis is a serious public health problem primarily affecting livestock workers. The strong seasonality of the disease indicates that climatic factors may play important roles in the transmission of the disease. However, the associations between climatic variability and human brucellosis are still poorly understood.

Methods: Data for a 14-year series of human brucellosis cases and seven climatic factors were collected in Yulin City from 2005 to 2018, one of the most endemic areas in northern China. Using cross-correlation analysis, the Granger causality test, and a distributed lag non-linear model (DLNM), we assessed the quantitative relationships and exposure-lag-response effects between monthly climatic factors and human brucellosis.

Results: A total of 7103 cases of human brucellosis were reported from 2005 to 2018 in Yulin City with a distinct peak between April and July each year. Seasonal fluctuations in the transmission of human brucellosis were significantly affected by temperature, sunshine duration, and evaporation. The effects of climatic factors were nonlinear over the 6-month period, and higher values of these factors usually increased disease incidence. The maximum separate relative risk (RR) was 1.36 (95\% confidence interval [CI], 1.03-1.81) at a temperature of $17.4^{\circ} \mathrm{C}$, $1.12(95 \% \mathrm{Cl}, 1.03-1.22)$ with $311 \mathrm{~h}$ of sunshine, and $1.18(95 \% \mathrm{Cl}, 0.94-1.48)$ with $314 \mathrm{~mm}$ of evaporation. In addition, the effects of these three climatic factors were cumulative, with the highest RRs of $2.27(95 \% \mathrm{Cl}, 1.09-4.57)$, 1.54 (95\% Cl, 1.10-2.18), and 1.27 (95\% Cl, 0.73-2.14), respectively.

Conclusions: In Yulin, northern China, variations in climatic factors, especially temperature, sunshine duration, and evaporation, contributed significantly to seasonal fluctuations of human brucellosis within 6 months. The key determinants of brucellosis transmission and the identified complex associations are useful references for developing strategies to reduce the disease burden.
\end{abstract}

Keywords: Human brucellosis, Climatic factors, Granger causality test, Distributed lag non-linear models, Quantitative associations

\footnotetext{
*Correspondence: 13759981783@163.com

${ }^{\dagger}$ Kun Liu and Zurong Yang contributed equally to this work.

'Department of Epidemiology, Ministry of Education Key Lab of Hazard Assessment and Control in Special Operational Environment, School of Public Health, Air Force Medical University, Xi'an 710032, China

Full list of author information is available at the end of the article
}

(c) The Author(s). 2020 Open Access This article is licensed under a Creative Commons Attribution 4.0 International License, which permits use, sharing, adaptation, distribution and reproduction in any medium or format, as long as you give appropriate credit to the original author(s) and the source, provide a link to the Creative Commons licence, and indicate if changes were made. The images or other third party material in this article are included in the article's Creative Commons licence, unless indicated otherwise in a credit line to the material. If material is not included in the article's Creative Commons licence and your intended use is not permitted by statutory regulation or exceeds the permitted use, you will need to obtain permission directly from the copyright holder. To view a copy of this licence, visit http://creativecommons.org/licenses/by/4.0/ The Creative Commons Public Domain Dedication waiver (http://creativecommons.org/publicdomain/zero/1.0/) applies to the data made available in this article, unless otherwise stated in a credit line to the data. 


\section{Background}

Brucellosis is a highly infectious zoonosis caused by bacteria of the genus Brucella spp. [1]. More than half a million new cases of brucellosis are reported in more than 170 countries each year, causing a serious human health burden and significant economic losses in agriculture, especially in developing countries in Asia, subSaharan Africa, and Latin America [2]. The disease is characterized by allergic reactions, symptoms with an incubation period of 5 days to 2 months, fever, migratory arthritis, night sweats, body aches, testicular pain and swelling, and weakness [3]. Human infections occur mainly through contact with infected livestock or aborted materials or consumption of unpasteurized food contaminated with Brucella spp., especially raw milk and other products from goat and sheep $[4,5]$. People of all ages and both sexes can be affected by the disease, and the occupational groups at higher risk of infection are shepherds, slaughterhouse workers, animal breeders, and veterinarians [3]. A field study reported that $79.4 \%$ of human infections occurred in individuals regularly in contact with domestic animals [6]. Given that Brucella spp. infections occur via various routes of diverse animal reservoirs and transmissions as well as the lack of effective vaccines and timely treatment, the rates of initial treatment failure and relapse along with the degree of substantial residual disability are high $[6,7]$.

In China, human brucellosis was first reported in Shanghai in 1905, and reporting to health authorities became mandatory in 1955 [8]. From 1955 to 2014, a total of 513,034 cases of human brucellosis and 170 deaths were registered, and 346,682 (67.6\%) cases were reported in the recent period from 2004 to 2014 [3]. In view of the fast-growing demand for milk and meat products, the incidence of brucellosis and the number of endemic areas have increased dramatically in China since 1999. To date, brucellosis is endemic in 30 of 32 provinces or autonomous regions of China, and the high-risk regions are mainly located in northern China, including the Inner Mongolia Autonomous Region and neighboring provinces $[7,9]$.

Outbreaks of human brucellosis in China usually have an obvious seasonal fluctuation and occur primarily between February and July [5, 9]. Previous studies showed that the seasonality of brucellosis might be linked to human activities and ecological factors, especially climatic variability $[10,11]$. Li et al. found that temporal peaks in the incidence of brucellosis were strongly associated with lower temperatures and less sunshine in the winter and spring [7]. Therefore, we hypothesized that climatic factors likely influence the ecology of brucellosis both directly and indirectly by affecting several parameters, including the growth and reproduction dynamics of domestic animals, interactions between sheep/goats and humans, pathogen replication, and population immunity [7, 10-12]. However, few studies have investigated the effects of climatic factors on this important zoonosis. In light of the growing burden of brucellosis, understanding the quantitative relationships between climatic factors and the seasonality of brucellosis and providing early

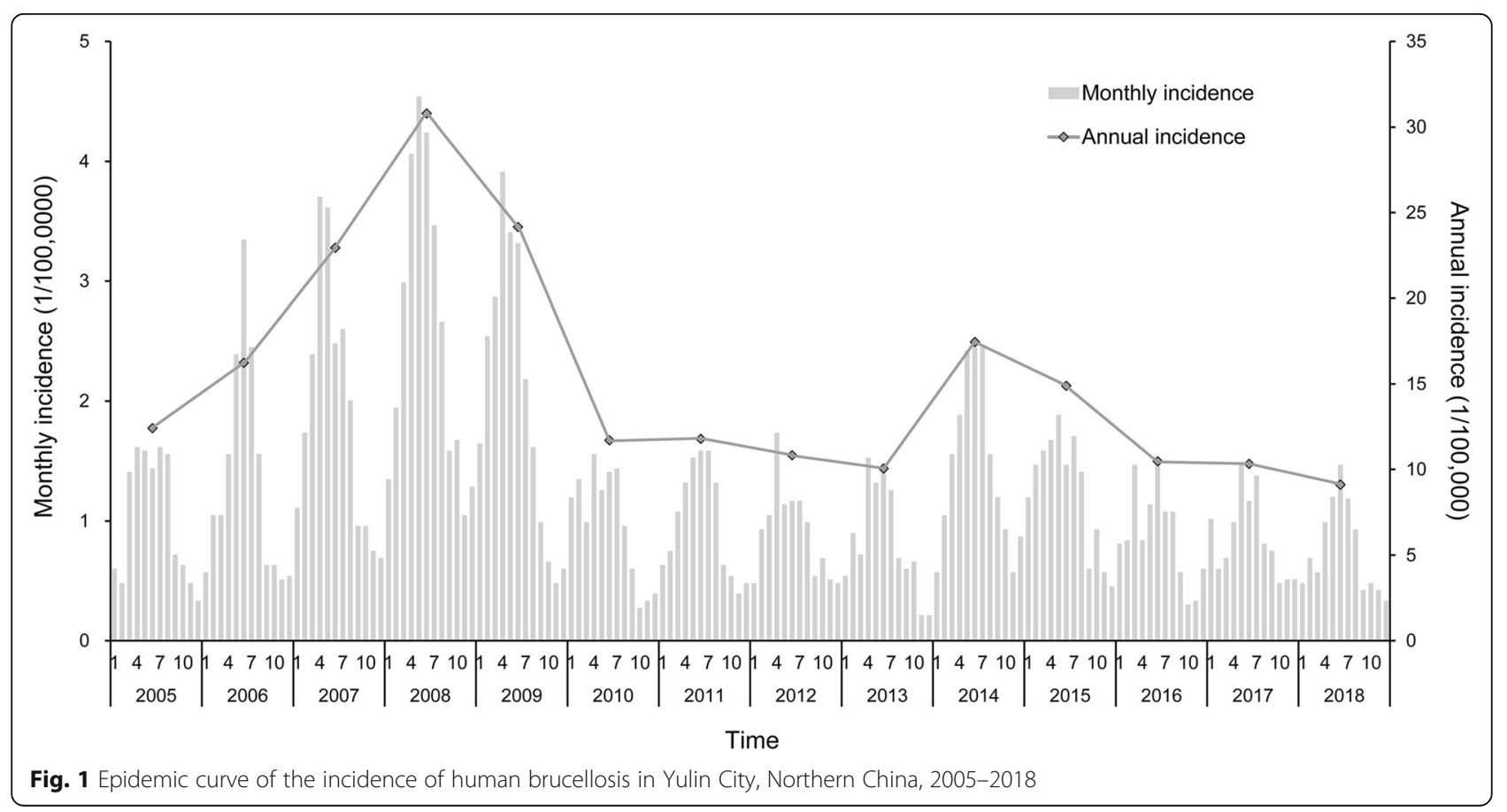


Table 1 Descriptive statistics of monthly climatic variables in Yulin City, Northern China, 2005-2018

\begin{tabular}{|c|c|c|c|c|c|c|}
\hline Variables & Min & $P_{25}$ & $P_{50}$ & $P_{75}$ & Max & Mean \pm SD \\
\hline Temperature $\left({ }^{\circ} \mathrm{C}\right)$ & -11.88 & 0.29 & 11.17 & 19.41 & 25.45 & $9.68 \pm 10.83$ \\
\hline Precipitation (mm) & 0 & 3.99 & 19.34 & 53.54 & 198.80 & $36.67 \pm 42.19$ \\
\hline Relative humidity (\%) & 23.99 & 42.38 & 50.46 & 62.57 & 77.80 & $51.69 \pm 12.60$ \\
\hline Sunshine duration (h) & 119.30 & 201.74 & 227.78 & 259.98 & 311.30 & $228.34 \pm 72.23$ \\
\hline Evaporation (mm) & 25.55 & 68.80 & 128.32 & 188.93 & 314.07 & $135.63 \pm 40.96$ \\
\hline Atmospheric pressure $(\mathrm{Pa})$ & 876.55 & 882.73 & 887.52 & 890.74 & 896.79 & $886.72 \pm 13.64$ \\
\hline Wind velocity $(\mathrm{m} / \mathrm{s})$ & 1.59 & 2.06 & 2.38 & 2.74 & 3.40 & $2.40 \pm 0.43$ \\
\hline
\end{tabular}

Min: minimum level of the variable; $P_{25}$ : 25th percentile of the variable; $P_{50}$ : 50th percentile of the variable; $P_{75}$ : 75 th percentile of the variable; Max: maximum level of the variable; SD: standard deviation

warning of disease epidemics through climate forecasting are critical needs.

In the current study, we selected one of the regions most severely affected by brucellosis in northern China. Data for a 14-year series were collected monthly, and mathematical models were adopted to evaluate exposure-lag-response effects and quantitative relationships between climatic variability and the incidence of human brucellosis.

\section{Materials and methods}

\section{Study area}

Yulin is a prefecture-level city of Shaanxi Province in northern China, bordered by the brucellosis high- prevalence provinces of Inner Mongolia, Shanxi, Gansu, and Ningxia, with a spatial extent of $36^{\circ} 57^{\prime}$ $39^{\circ} 34^{\prime} \mathrm{N}$ and $107^{\circ} 28^{\prime}-115^{\circ} 15^{\prime} \mathrm{E}$ (Fig. S1). It consists of 2 districts and 10 counties with area of $43,578 \mathrm{~km}^{2}$ and a total population of $3,382,000$ in 2016. The region belongs to a part of the transitional landscape spanning from the Maowusu Desert to the Loess Plateau and is a typical crisscross zone of animal husbandry and farming. The climate of the region is typical of northern China, i.e., temperate arid and semi-arid with continental monsoons, cold and long winters, hot and slightly humid summers (http://www. yl.gov.cn/).

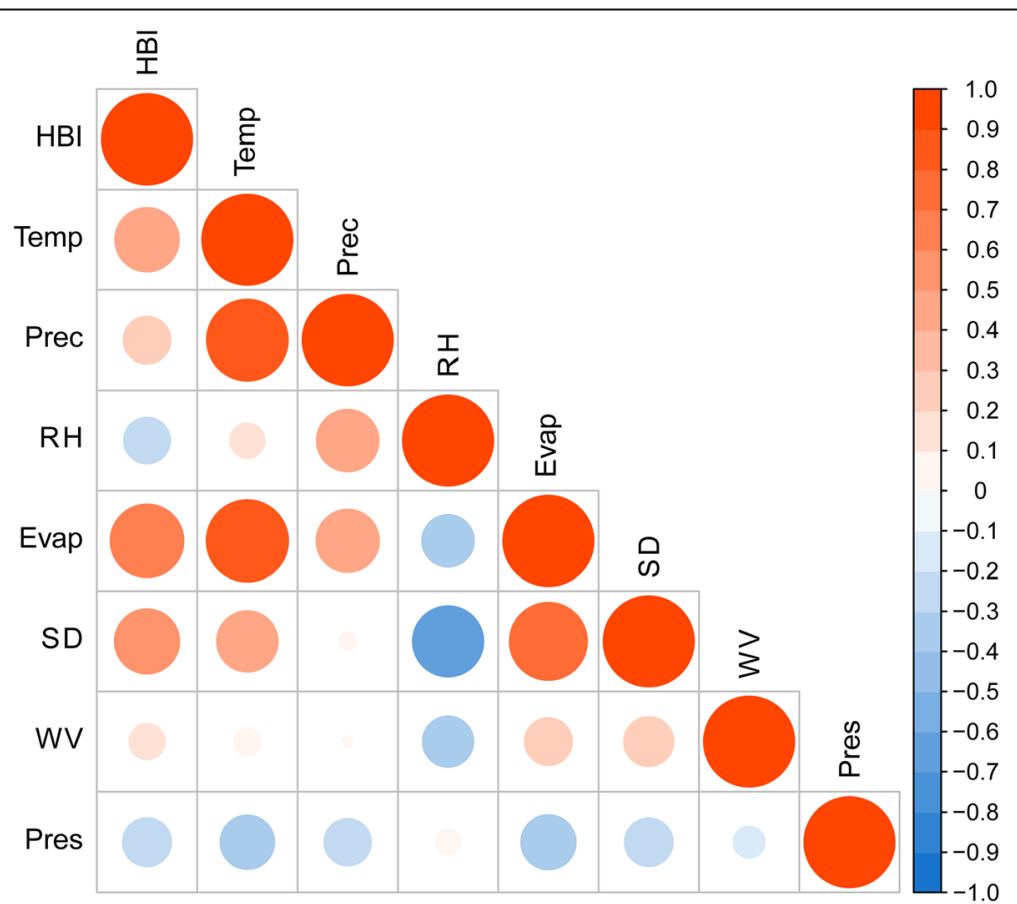

Fig. 2 Cross correlation coefficients between climatic factors and the incidence of human brucellosis in Yulin City, Northern China, 2005-2018. (IHB: monthly incidence of human brucellosis; Temp: monthly mean temperature; Prec: monthly mean precipitation; Evap: monthly cumulative evaporation; SD: monthly cumulative sunshine duration; RH: monthly mean relative humidity; Pres: monthly mean atmospheric pressure; WV: monthly mean wind velocity) 
Table 2 Granger causality tests for climatic variables and the monthly incidence of human brucellosis in Yulin City, Northern China, 2005-2018

\begin{tabular}{llllllll}
\hline & Temperature & Precipitation & Relative humidity & Sunshine duration & Evaporation & Atmospheric pressure & Wind velocity \\
\hline F-statistics & 2.358 & 1.439 & 0.827 & 3.625 & 2.579 & 3.741 & 3.520 \\
$P$-value & $0.033^{*}$ & 0.204 & 0.551 & $0.002^{*}$ & $0.021^{*}$ & 0.067 & 0.769 \\
\hline$* P<0.05$ & & & & &
\end{tabular}

\section{Data collection}

In China, human brucellosis is considered a notifiable category B infectious disease, and human cases must be reported to the local Center for Disease Control and Prevention (CDC). A confirmed case of brucellosis is diagnosed based on a combination of epidemiologic exposure, clinical signs, and verification of infection by serological tests, including the standard plate agglutination test and/or rose bengal plate test and/or serum agglutination test, or isolation of Brucella spp. according to the guidelines of the World Health Organization. In this study, consecutive data of confirmed brucellosis cases from January 1, 2005 to December 31, 2018 were collected from the CDC of Shaanxi Province, and demographic data were obtained from the Sixth National Census in 2010. Data on seven local climatic variables-temperature, precipitation, relative humidity, sunshine duration, evaporation, atmospheric pressure, and wind velocitywere collected daily during the study period by the Chinese Bureau of Meteorology (http://data.cma.cn/).

\section{Statistical analysis}

Considering the incubation period of human brucellosis and the data stability, a monthly timeseries analysis was conducted to determine the temporal associations between climatic factors and the incidence of human brucellosis. First, climatic factors and the incidence rates of human brucellosis were described, and a cross-correlation analysis was performed to assess correlations. Next, a Granger causality test was performed for each climatic factor to determine the likely effect of climate variability on the transmission of human brucellosis. Final, the variables selected in the Granger causality test were included in a distributed lag non-linear model (DLNM) to examine their non-linear and lagged effects on the disease transmission. The methodology is based on the definition of a cross-basis, which is a function expressed by the combination of two sets of basic functions that specify the relationships in the dimension of predictor and time lags, respectively $[13,14]$. The structure of the DLNM was as follows:

$$
\begin{aligned}
& Y_{t} \sim \text { Poisson }\left(\mu_{t}\right) \\
& \log \left(\mathrm{E}\left(\mathrm{Y}_{t}\right)\right)=\alpha+\beta T_{t, l}+N S(\text { time })+\text { month }
\end{aligned}
$$

where $\mathrm{t}$ is the month of the observation; $Y_{t}$ is the observed incidence of brucellosis in month $\mathrm{t} ; \alpha$ is the intercept; $T_{t, l}$ is a matrix obtained by applying the DLNM to climatic factors, $\beta$ is the vector of coefficients for $T_{t, l}$, and $l$ is the time lag. Four degrees of freedom per year were used to adequately control for the seasonality of brucellosis transmission. Month is an ordinal variable for the month of the year. A spline-natural cubic spline for climatic factors that generated a basis matrix of polynomials was used to simulate the non-linear effect and the lag effect. The average value for each variable was defined as the baseline reference for calculating the RR, and the separate effect (in a specific lag month) and cumulative effect (in all months preceding a specific lag month) on the incidence of brucellosis were calculated.

The analyses were performed using $\mathrm{R}$ software version 3.5.1 with the packages "lmtest" and "dlnm". All statistical tests were two-sided, and a $p$ value $<0.05$ was considered statistically significant.

\section{Ethical statement}

The National Health Commission of China determined whether ethical approval was required for this study. In China, the collection of data from human brucellosis cases was part of routine public health surveillance, and such data collection was exempt from institutional review board assessment $[15,16]$.

\section{Results}

Temporal trend and seasonality of human brucellosis and climatic factors

In the period from 2005 to 2018, a total of 7103 cases of human brucellosis were reported in the study area. The annual average incidence of the disease was 15.24 per 100,000 persons, and the highest rate was $30.79 / 100,000$ in 2008. The epidemic curves revealed a seasonal peak in incidence from April to July, accounting for $51.33 \%$ of all cases. In addition, the mean and standard deviation of the monthly incidence was $1.27 \pm 0.86$ per 100,000 , and the incidence was highest in May (Fig. 1). Summary statistics for the climatic factors in the study period are shown in Table 1. The cross-correlation analysis revealed that five climatic factors-temperature, precipitation, evaporation, sunshine duration, and wind velocity-were positively correlated with the human brucellosis incidence, and relative humidity and atmospheric 

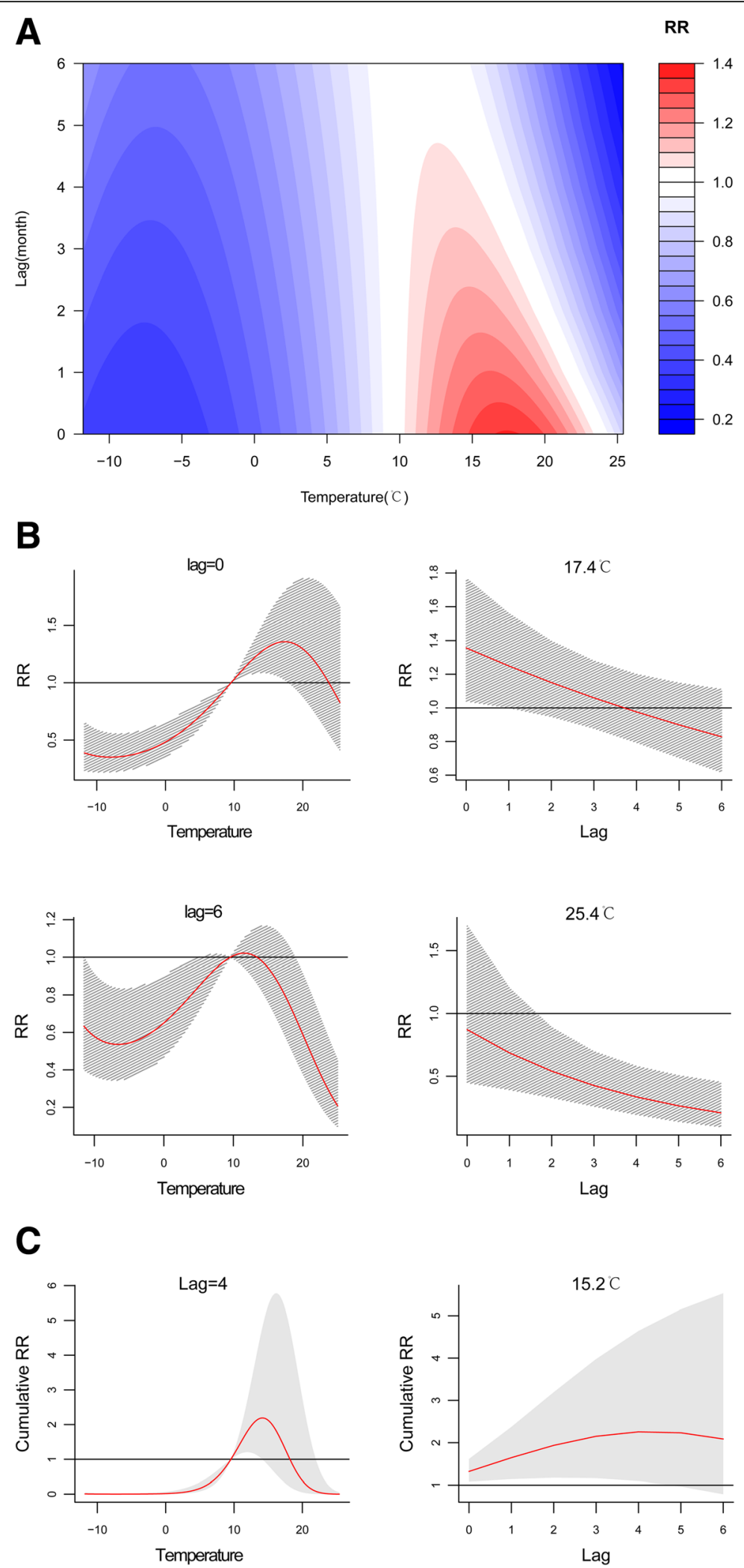

Fig. 3 (See legend on next page.) 
(See figure on previous page.)

Fig. 3 a Contour plots of the combined effect of time lags and temperature on the relative risk of transmission of human brucellosis. $\mathbf{b}$. Effect of specific temperatures and time lags on the relative risk of transmission of human brucellosis. The red lines indicate the mean relative risk, and the gray lines are $95 \% \mathrm{Cl}$. c. Effect of specific temperatures and time lags on the cumulative risk of transmission of human brucellosis. The red lines indicate the mean relative risk, and the gray areas correspond to $95 \% \mathrm{Cl}$

pressure were negatively associated with the disease incidence (Fig. 2 and Table S1). The results of the Granger causality tests indicated that the temporal distribution of human brucellosis was strongly affected by temperature, sunshine duration, and evaporation (Table 2).

\section{Non-linear and lagged effects of climatic factors on the incidence of human brucellosis Temperature}

A comprehensive summary of the non-linear relationship between monthly average temperature and the incidence of human brucellosis over a 6-month period is shown in Fig. 3a. The RR of human brucellosis increased significantly for 3 to 4 months as the temperature increased (Figure S2). The separate effects of different temperatures and two time lags ( 0 and 6 months) on the RRs together with 95\% confidence intervals $(95 \% \mathrm{CI})$ are shown in Fig. 3b. The association presented an inverted U-shaped function, i.e., as temperature increased, the RR values increased to a peak value and then decreased. The maximum RR was 1.36 (95\% CI, 1.03-1.81) at approximately $17.4{ }^{\circ} \mathrm{C}$ in the current month (time lag 0 ), and the minimum $\mathrm{RR}$ was 0.19 (95\% CI, 0.08-0.42) at approximately $25.4{ }^{\circ} \mathrm{C}$ at time lag 6 (Table 3). The effect of temperature on the cumulative risk of disease is shown in Fig. 3c. Higher temperatures increased the cumulative risk from time lag 0 to 4 , and the RR of 2.27 (95\% CI, 1.09-4.57) was highest at approximately $15.2^{\circ} \mathrm{C}$ in month 4 sss.

\section{Duration of sunshine}

The combined effect of time lag and duration of sunshine on the RR of human brucellosis is shown in Fig. 4a. A longer sunshine duration significantly increased the $R R$ for all lag times compared with the average duration, whereas a shorter sunshine duration decreased the RR (Figure S3). The effects of sunshine duration were strongest in time lag 0 , with a maximum RR of $1.12(95 \% \mathrm{CI}, 1.03-1.22)$ at $311 \mathrm{~h}$ and a minimum RR of 0.86 (95\% CI, 0.78-0.96) at $121 \mathrm{~h}$ (Fig. 4b and Table 3). There was a significantly positive association between sunshine duration and cumulative RR for all time lags, and the effect was higher as the sunshine duration increased. The cumulative RR was highest of 1.54 (95\% CI, 1.10-2.18) at $311 \mathrm{~h}$ with time lag 6 (Fig. 4c and Table 3).

\section{Evaporation}

The combined effect of time lags and evaporation on the RR of human brucellosis is shown in Fig. 5a. Higher evaporation increased the $R R$ in the short terms (within 2 months) and then decreased over time. In contrast, lower evaporation decreased the $\mathrm{RR}$ in the short terms (within 2 months) and increased the RR over time (Figure S4). The variations in $\mathrm{RR}$ at $314 \mathrm{~mm}$ were biggest, with a maximum $\mathrm{RR}$ of 1.18 (95\% CI, 0.94-1.48) in time lag 0 and a minimum RR of 0.67 (95\% CI, 0.50-0.10.91) in time lag 6 (Fig. $5 \mathrm{~b}$ and Table 3 ). The cumulative $\mathrm{RR}$ of 1.27 (95\% CI, 0.73-2.14) was highest at approximately $314 \mathrm{~mm}$ (Fig. 5c and Table 3).

\section{Discussion}

Human brucellosis is a serious public health problem in the global livestock husbandry areas, and the seasonal distribution of the disease is strongly associated with climate variability $[2,7]$. The critical findings of our study were that temperature, sunshine duration,

Table 3 DNLM model results for separate and cumulative effects of monthly climatic variables on the relative risk of human brucellosis in Yulin City, Northern China, 2005-2018

\begin{tabular}{|c|c|c|c|c|c|c|c|c|c|}
\hline \multirow[t]{2}{*}{ Variable } & \multicolumn{6}{|l|}{ Separate effect } & \multicolumn{3}{|l|}{ Cumulative effect } \\
\hline & $\begin{array}{l}\text { Maximum RR } \\
(95 \% \mathrm{Cl})\end{array}$ & $\begin{array}{l}\text { Variable } \\
\text { value }\end{array}$ & $\begin{array}{l}\text { Lag } \\
\text { month }\end{array}$ & $\begin{array}{l}\text { Minimum RR } \\
(95 \% \mathrm{Cl})\end{array}$ & $\begin{array}{l}\text { Variable } \\
\text { value }\end{array}$ & $\begin{array}{l}\text { Lag } \\
\text { month }\end{array}$ & $\begin{array}{l}\text { Maximum RR } \\
(95 \% \mathrm{Cl})\end{array}$ & $\begin{array}{l}\text { Variable } \\
\text { value }\end{array}$ & $\begin{array}{l}\text { Lag } \\
\text { month }\end{array}$ \\
\hline Temperature $\left({ }^{\circ} \mathrm{C}\right)$ & $1.36(1.03-1.81)$ & $17.4^{\circ} \mathrm{C}$ & 0 & $0.19(0.08-0.42)$ & $25.4^{\circ} \mathrm{C}$ & 6 & $2.27(1.09-4.57)$ & $15.2^{\circ} \mathrm{C}$ & 4 \\
\hline $\begin{array}{l}\text { Sunshine } \\
\text { duration (h) }\end{array}$ & $1.12(1.03-1.22)$ & $311 \mathrm{~h}$ & 0 & $0.86(0.78-0.96)$ & $121 \mathrm{~h}$ & 0 & $1.54(1.10-2.18)$ & $311 \mathrm{~h}$ & 6 \\
\hline $\begin{array}{l}\text { Evaporation } \\
(\mathrm{mm})\end{array}$ & $1.18(0.94-1.48)$ & 314 mm & 0 & $0.67(0.50-10.91)$ & 314 mm & 6 & $1.27(0.73-2.14)$ & 314 mm & 2 \\
\hline
\end{tabular}



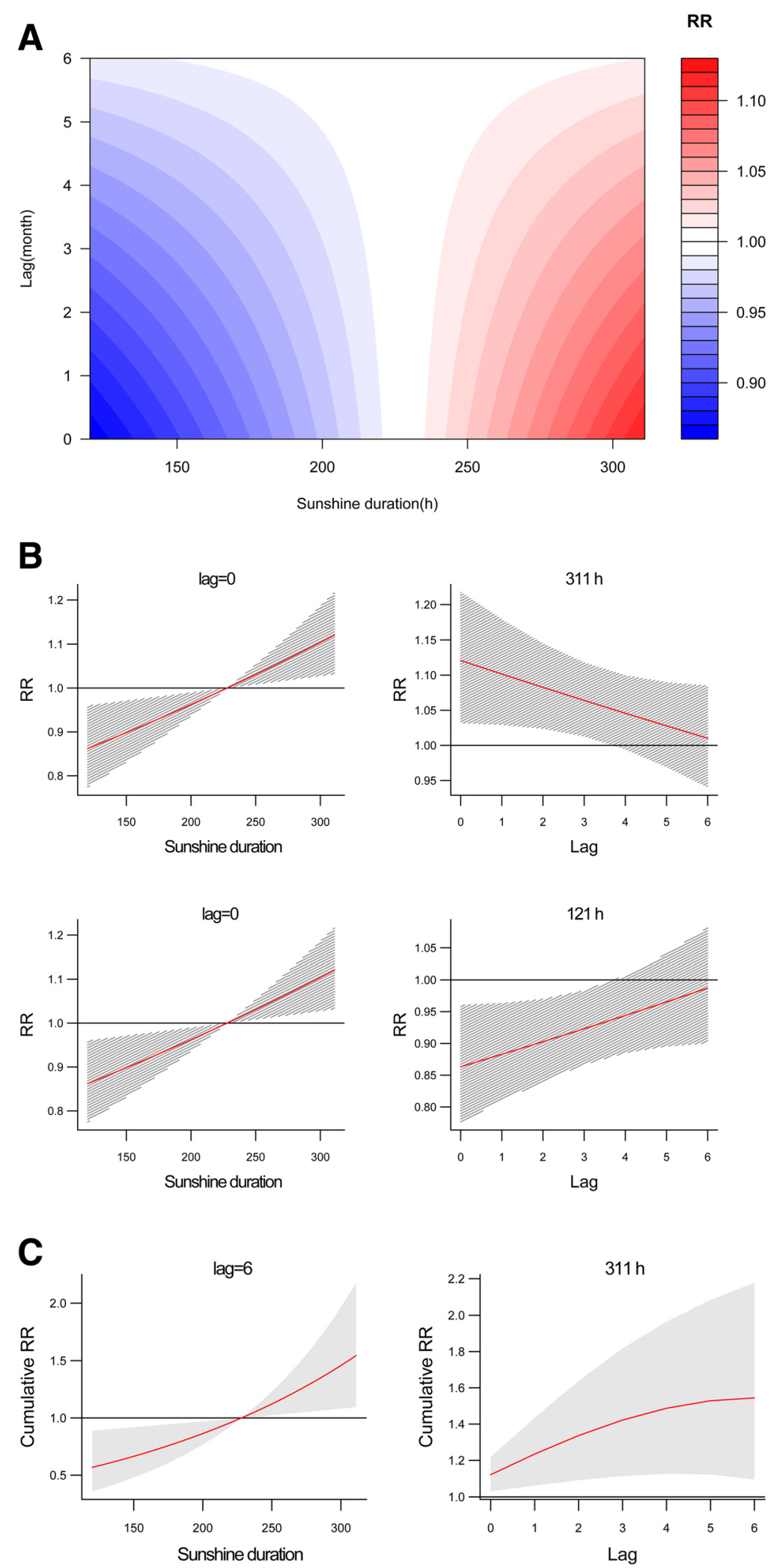

Fig. 4 (See legend on next page.) 
(See figure on previous page.)

Fig. 4 a Contour plots of the combined effect of time lags and sunshine duration on the relative risk of transmission of human brucellosis. $\mathbf{b}$. Effect of specific sunshine durations and time lags on the relative risk of transmission of human brucellosis. The red lines are the mean relative risks, and the gray lines are $95 \% \mathrm{Cl}$. c. Effects of specific sunshine durations and time lags on the cumulative risk of transmission of human brucellosis. The red lines are the mean relative risks, and the gray areas are $95 \% \mathrm{Cl}$

and evaporation were key determinants of disease seasonality in Yulin, and similar associations could easily be expanded over wider regions in northern China. Meanwhile, the lagged effects of climatic factors could provide sufficient time to develop targeted interventions for decreasing the disease burden in humans and livestock.

Seasonal climatic conditions may affect multiple aspects of climate-sensitive infectious diseases [17]. Consequently, climatic factors can be used to forecast the occurrence of disease outbreaks within periods of weeks to months [18]. Public health professionals use mathematical models to investigate the complex relationships between disease epidemics and climate data [19]. The DLNM was conducted in the study to examine the quantitative relationships and exposurelag-response effects between climate variability and human brucellosis. This model has been effectively adopted to assess the non-linear relationships between meteorological factors and infectious diseases such as dengue, malaria, hand-foot-mouth disease, tuberculosis, and mumps [20-25].

The results of the present study suggest that changes in temperature may have a greater impact on the epidemics of human brucellosis than other climatic factors. The increasing temperature increased Brucella spp. development and replication in the host and increased the frequency of exposure of susceptible animals and humans [7]. Therefore, the transmission and persistence of Brucella spp. may be enhanced in warmer conditions, as demonstrated in our study, in which the maximum cumulative effect was highest at $15.2^{\circ} \mathrm{C}$ in 4 months. In this respect, higher temperatures in late spring and early summer increase husbandry activities for sheep and goats, including shearing, breeding, processing of meat products, and commercialization of sheep products, consequently increasing the exposure of susceptible animals to contaminated animal products $[11,26]$. In contrast, the RR of brucellosis transmission decreases during winter because colder temperatures may limit the development of infective organisms [27]. In addition, Yulin is a region known for cashmere production and sheep farming. Meanwhile, the quarantine measures in sheep farms, adequate management of animal abortion products, and human protective measures are all deficient, causing more people to be exposed to the contaminated animal products [28, 29].

The variability in monthly cumulative evaporation and sunshine strongly affects the transmission of Brucella spp., which develops intracellularly in the host and outside the host in dust, soil, and water $[11,26,27]$. The high incidence of brucellosis may be partly due to sheep breeding and abortion in subsequent lambing $[7,23]$. Considering that the gestation period in sheep is 6 months, our results suggest that the increased sunshine duration in early winter could promote estrus in sheep, resulting in the birth of animals more susceptible to infections with the adoption of high-risk breeding activities [12]. In addition, higher levels of evaporation and sunshine may favor drought, limiting plant germination. Meanwhile, dry environments may cause human skin dryness and fissures, increasing the exposure risk. As for China, the national policy of converting farmland into forests has limited field grazing, and breeding methods for sheep and goats have been adapted to raising livestock in pens [28]. However, the levels of minerals in stored grasses cultivated are unbalanced, making sheep and goats immunologically compromised and more susceptible to diseases [29].

This study aimed to investigate the effects of climatic factors on the incidence of human brucellosis, and several limitations should be acknowledged. First, the data were obtained from a passive surveillance system, in which some cases of human brucellosis might not have been reported because of milder clinical symptoms or delayed reporting in rural areas [30]. Second, the temporal dynamics of brucellosis are affected by nonclimatic factors as well, including the number of affected sheep, immunity of the local population, human activities and movements, commercialization of sheep products, and eating habits. The analytical capability of model may be limited because of omitted covariates or changes in environmental and human factors. These limitations should be further investigated.

\section{Conclusion}

The present study provides evidence for a strong relationship between climatic factors and the incidence of human brucellosis in Yulin City, and the results 

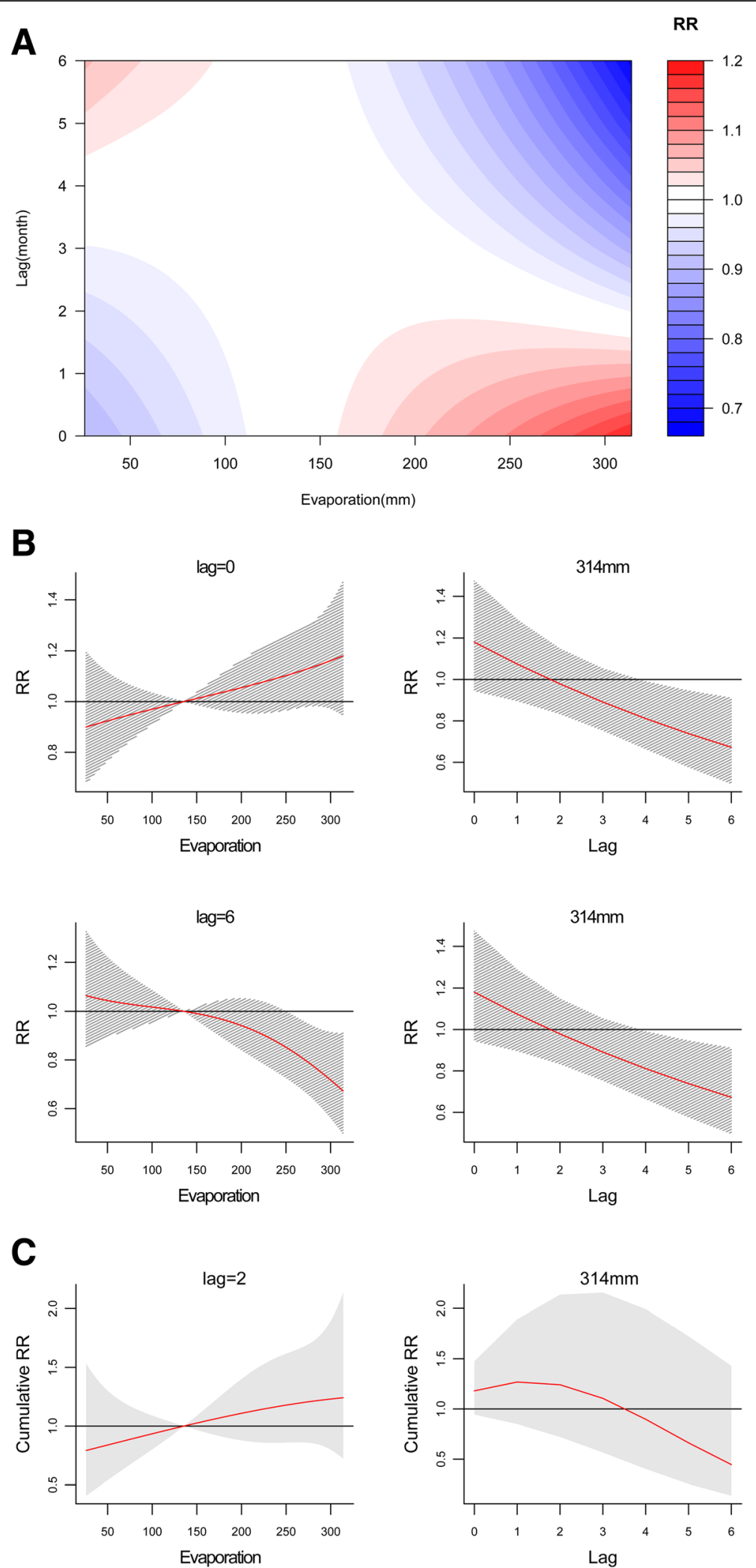

Fig. 5 (See legend on next page.) 
(See figure on previous page.)

Fig. 5 a. Contour plots of the combined effect of evaporation and time lags on the relative risk of transmission of human brucellosis. $\mathbf{c}$. Effects of specific evaporations and time lags on the relative risk of transmission of human brucellosis. The red lines are the mean relative risks, and the gray lines are $95 \% \mathrm{Cl}$. c. Effect of specific evaporations and time lags on the cumulative risk of transmission of human brucellosis. The red lines are the mean relative risks, and the gray areas are $95 \% \mathrm{Cl}$

can be replicated easily in livestock husbandry areas with similar environmental conditions. The key determinants of brucellosis transmission and the identified complex associations are useful references for the development of strategies for early warning, prevention, and control of seasonal epidemics.

\section{Supplementary information}

Supplementary information accompanies this paper at https://doi.org/10. 1186/s12889-020-08599-4.

Additional file 1: Table S1. Cross correlation coefficients between monthly human brucellosis incidence and climatic variables in Yulin City, the Northern China, 2005-2018. Figure S1. Study areas in China. The map was created by Kun Liu in ArcGIS 10.2 Software, ESRI Inc., Redlands, CA, USA, (https://www.arcgis.com/index.html).Figure S2. Threedimensional graph of the relationship between monthly mean temperature and human brucellosis incidence. Figure S3. Threedimensional graph of the relationship between monthly cumulative sunshine duration and human brucellosis incidence. Figure S4. Threedimensional graph of the relationship between monthly cumulative evaporation and human brucellosis incidence.

\section{Abbreviations}

CDC: Center for Disease Control and Prevention; Cl: Confidence interval; DLNM: Distributed lag non-linear model; Evap: Monthly cumulative evaporation; IHB: Monthly incidence of human brucellosis; Prec: Monthly mean precipitation; Pres: Monthly mean atmospheric pressure; $\mathrm{RH}$ : Monthly mean relative humidity; RR: Relative risk; SD: Monthly cumulative sunshine duration; Temp: Monthly mean temperature; WV: Monthly mean wind velocity

\section{Acknowledgements}

The authors thank all medical staff and health practitioners who have contributed to the reporting of human brucellosis in Yulin City.

\section{Authors' contributions}

$\mathrm{KL}$ and ZJS designed the study. ZRY, KL, WFL, TCG, YL and ZJS performed data collection, analysis and modeling. $\mathrm{KL}$ and ZRY wrote and revised the draft. All authors read and approved the final manuscript.

\section{Funding}

This work was supported by the National Natural Science Foundation of China (81803289), China Special Grant for the Prevention and Control of Infection Diseases (2017ZX10105011), and the Natural Science Foundation of Shaanxi Province (2020JM-329, 2017Q8015). The funding agencies had no role in the study design, data collection and analysis, or preparation of the manuscript.

\section{Availability of data and materials}

The data of brucellosis patients in Yulin city are available from Shaanxi Province Center for Disease Control and Prevention. All data used for analysis are available upon a proper request from the corresponding author Zhongjun Shao at 13759981783@163.com.

\section{Ethics approval and consent to participate}

Not applicable.

The National Health Commission of China determined whether ethical approval was required for this study. In China, the collection of data from human brucellosis cases was part of routine public health surveillance, and such data collection was exempt from institutional review board assessment $[15,16]$.

\section{Consent for publication}

Not applicable.

\section{Competing interests}

The authors declare that they have no competing interests.

\section{Author details}

${ }^{1}$ Department of Epidemiology, Ministry of Education Key Lab of Hazard Assessment and Control in Special Operational Environment, School of Public Health, Air Force Medical University, Xi'an 710032, China. ${ }^{2}$ Health Commission of Shaanxi Province, Xi'an 710003, China.

Received: 8 July 2019 Accepted: 26 March 2020

Published online: 16 April 2020

References

1. Hueffer K, Parkinson AJ, Gerlach R, Berner J. Zoonotic infections in Alaska: disease prevalence, potential impact of climate change and recommended actions for earlier disease detection, research, prevention and control. Int J Circumpolar Health. 2013;72. https://doi.org/10.3402/ijch.v72i0.19562.

2. Dadar M, Shahali Y, Whatmore AM. Human brucellosis caused by raw dairy products: a review on the occurrence, major risk factors and prevention. Int J Food Microbiol. 2019;292:39-47. https://doi.org/10.1016/j.ijfoodmicro.2018. 12.009 .

3. Lai S, Zhou H, Xiong W, Gilbert M, Huang Z, Yu J, et al. Changing epidemiology of human brucellosis, China, 1955-2014. Emerging Infect Dis. 2017;23(2):184-94. https://doi.org/10.3201/eid2302.151710.

4. Lou P, Wang L, Zhang X, Xu J, Wang K. Modelling Seasonal Brucellosis Epidemics in Bayingolin Mongol Autonomous Prefecture of Xinjiang, China, 2010-2014. Biomed Res Int. 2016;2016:5103718. https://doi.org/10.1155/ 2016/5103718.

5. Nematollahi S, Ayubi E, Karami M, Khazaei S, Shojaeian M, Zamani R, et al. Epidemiological characteristics of human brucellosis in Hamadan Province during 2009-2015: results from the National Notifiable Diseases Surveillance System. Int J Infect Dis. 2017;61:56-61. https://doi.org/10.1007/s11250-0130375-6.

6. Chen Q, Lai S, Yin W, Zhou H, Li Y, Mu D, et al. Epidemic characteristics, high-risk townships and space-time clusters of human brucellosis in Shanxi Province of China, 2005-2014. BMC Infect Dis. 2016;16(1):760. https://doi.org/ 10.1186/s12879-016-2086-X.

7. Li YJ, Li XL, Liang S, Fang LQ, Cao WC. Epidemiological features and risk factors associated with the spatial and temporal distribution of human brucellosis in China. BMC Infect Dis. 2013;13(547):1-12. https://doi.org/10. 1186/1471-2334-13-547.

8. Shang DQ, Xiao DL, Yin JM. Epidemiology and control of brucellosis in China. Vet Microbiol. 2002;90:165-82. https://doi.org/10.1016/s03781135(02)00252-3.

9. Guan P, Wu W, Huang D. Trends of reported human brucellosis cases in mainland China from 2007 to 2017: an exponential smoothing time series analysis. Environ Health Prev Med. 2018;23(1):23. https://doi.org/10.1186/ s12199-018-0712-5.

10. Rodriguez-Morales AJ. Climate change, climate variability and brucellosis. Recent Pat Antiinfect Drug Discov. 2013;8(1):4-12. https://doi.org/10.2174/ $1574891 \times 11308010003$

11. Zhu HS, Wang FL, Lin DH, Hong ST, Ou JM, Chen W, et al. Analysis on epidemiology and spatial-temporal clustering of human brucellosis in Fujian province, 2011-2016. Chin J Epidemiol. 2017;38(9):1212-7. https://doi.org/10. 3760/cma.j.issn.0254-6450.2017.09.014

12. Yang ZR, Li X, Shao ZJ, Ma WT, Yuan XJ, Wu KJ, et al. Characteristics on spatial and temporal distribution as well as the driving effect of 
meteorological factors on brucellosis in Datong city, Shanxi province, 20052015. Chin J Epidemiol. 39(9):1165-71. https://doi.org/10.3760/cma.jissn. 0254-6450.2018.09.005.

13. Gasparrini A, Armstrong B, Kenward MG. Distributed lag non-linear models. Stat Med. 2010;29(21):2224-34. https://doi.org/10.1002/sim.3940.

14. Gasparrini A. Distributed Lag Linear and Non-Linear Models in R: The Package dlnm. J Stat Softw. 2011;43(8):1-20. https://doi.org/10.18637/jss.v043.108.

15. Chen WJ, Lai SJ, Yang Y, Liu K, Li XL, Yao HW, et al. Mapping the distribution of Anthrax in mainland China, 2005-2013. PLoS Negl Trop Dis. 2016;10(4):e0004637. https://doi.org/10.1371/journal.pntd.0004637.

16. Sun RX, Lai SJ, Yang Y, Li XL, Liu K, Yao HW, et al. Mapping the distribution of tick-borne encephalitis in mainland China. Ticks Tick-borne Dis. 2017;8(4): 631-9. https://doi.org/10.1016/.tttbdis.2017.04.009.

17. Xiang J, Hansen A, Liu Q, Tong MX, Liu X, Sun Y, et al. Impact of meteorological factors on hemorrhagic fever with renal syndrome in 19 cities in China, 2005-2014. Sci Total Environ. 2018;636:1249-56. https://doi. org/10.1016/j.scitotenv.2 018.04.407.

18. Morin CW, Semenza JC, Trtanj JM, Glass GE, Boyer C, Ebi KL. Unexplored opportunities: use of climate- and weather-driven early warning systems to reduce the burden of infectious diseases. Curr Environ Health Rep. 2018;5(4): 430-8. https://doi.org/10.1007/s40572-018-0221-0.

19. Yang L, Bi ZW, Kou ZQ, Li XJ, Zhang M, Wang M, et al. Time-series analysis on human brucellosis during 2004-2013 in Shandong Province, China. Zoonoses Public Health. 2015;62(3):228-35. https://doi.org/10.1111/zph.12145.

20. Iguchi JA, Seposo XT, Honda Y. Meteorological factors affecting dengue incidence in Davao, Philippines. BMC Public Health. 2018;18(1):629.

21. Chien LC, Yu HL. Impact of meteorological factors on the spatiotemporal patterns of dengue fever incidence. Environ Int. 2014;73:46-56. https://doi. org/10.1016/j. envint. 2014.06.018.

22. Hu W, Li Y, Han W, Xue L, Zhang W, Ma W, Bi P. Meteorological factors and the incidence of mumps in Fujian Province, China, 2005-2013: Non-linear effects. Sci Total Environ. 2018;619-620:1286-98. https://doi.org/10.1016/j. scitotenv. 2017.11.108.

23. Kim YM, Park JW, Cheong HK. Estimated effect of climatic variables on the transmission of plasmodium vivax malaria in the Republic of Korea. Environ Health Perspect. 2012;120(9):1314-9. https://doi.org/10.1289/ehp.1104577.

24. Xiao Y, He L, Chen Y, Wang Q, Meng Q, Chang W, et al. The influence of meteorological factors on tuberculosis incidence in Southwest China from 2006 to 2015. Sci Rep. 2018;8(1):10053. https://doi.org/10.1038/s41598-01828426-6.

25. Yu G, Li Y, Cai J, Yu D, Tang J, Zhai W, et al. Short-term effects of meteorological factors and air pollution on childhood hand-foot-mouth disease in Guilin. China Sci Total Environ. 2019;646:460-70. https://doi.org/ 10.1016/.scitotenv.2018.07.329

26. Lee HS, Her M, Levine M, Moore GE. Time series analysis of human and bovine brucellosis in South Korea from 2005 to 2010. Prev Vet Med. 2013; 110(2):190-7. https://doi.org/10.1016/j.prevetmed.2012.12.003.

27. Oseguera Montiel D, Frankena K, Udo H, Keilbach Baer NM, Van der Zijpp A. Prevalence and risk factors for brucellosis in goats in areas of Mexico with and without brucellosis control campaign. Trop Anim Health Prod. 2013; 45(6):1383-9. https://doi.org/10.1007/s11250-013-0375-6.

28. Li XC, JF H. Study on the status and countermeasures of grass industry formation and sheep raising in Yulin City. J Yulin College. 2007;16:1-3.

29. Bai CS, Liu JP, YQ X: Practice in the progressive control path of brucellosis based on risk factors analysis. Chin Anim Heal Inspect 2017, 34:5-9. DOI: https://doi.org/10.3969/j.issn.1005-944X.2017.12.00.

30. Zeng L, Yang WW, Tie P, Liu XR, Gao XR, Li ZY, et al. Investigation of human brucellosis diagnosis and report quality in medical institutions in key areas of Shanxi province. Chin J Epidemiol 2017, 38(11):1480-1483. DOl: https://doi.org/10.3760/cma.j.issn.0254-6450.2017.11.008.

\section{Publisher's Note}

Springer Nature remains neutral with regard to jurisdictional claims in published maps and institutional affiliations.

Ready to submit your research? Choose BMC and benefit from:

- fast, convenient online submission

- thorough peer review by experienced researchers in your field

- rapid publication on acceptance

- support for research data, including large and complex data types

- gold Open Access which fosters wider collaboration and increased citations

- maximum visibility for your research: over $100 \mathrm{M}$ website views per year

At $\mathrm{BMC}$, research is always in progress.

Learn more biomedcentral.com/submissions 